\title{
Gênero, feminismo e Serviço Social - encontros e desencontros ao longo da história da profissão
}

\author{
Teresa Kleba Lisboa \\ Universidade Federal de Santa Catarina (UFSC)
}

Gênero, feminismo e Serviço Social - encontros e desencontros ao longo da história da profissão Resumo: Este artigo aponta a crescente demanda de situações que perpassam a questão de gênero no cotidiano de intervenção dos assistentes sociais; discute o descompasso entre o Serviço Social e os estudos feministas traçando um paralelo entre as trajetórias dos dois enfoques ao longo da história. Faz uma crítica ao submetimento da profissão às teorias androcêntricas que exerceram poder e dominação na produção de conhecimento. Sugere que as teorias feministas e os estudos de gênero constituem-se um aporte teóricometodológico significativo para o Serviço Social. Polemiza "como garantir igualdade com respeito às diferenças", aponta as principais áreas críticas que impedem o desenvolvimento das mulheres e demarcam a desigualdade de gênero, e conclui que a adoção da perspectiva de gênero nas mediações teóricas lança um novo olhar sobre a realidade, a partir das mulheres e com as mulheres, revolucionando a ordem dos poderes e dos submetimentos.

Palavras-chave: Serviço Social, estudos feministas, relações de gênero.

Gender, Feminism and Social Work: Approximations and Conflicts in the History of the Profession Abstract: This article looks at the growing needs found in situations that involve the issue of gender in the common intervention of social workers. It discusses the gap between social work and feminist studies, by sketching a historic parallel between the trajectories of the two fields. It criticizes the submission of the profession to andro-centric theories that exercise power and control in the production of knowledge. It suggests that feminist theories and gender studies provide significant theoretical and methodological support for social work. The paper questions "how to guarantee equality while respecting differences," and points to the principal critical areas that impede the development of women and mark gender inequality. It concludes that the adoption of a gender perspective in theoretical mediations allows a new look at reality, based on women and with women, revolutionizing the order of power and submission.

Key words: Social Work, feminist studies, gender relations. 


\section{Introdução}

A partir de minha experiência como docente do curso de Serviço Social, coordenando projetos de extensão e participando de grupos e organizações sociais ao longo de aproximadamente 20 anos, chamoume atenção que no processo de construção do conhecimento, ao longo da história da profissão, uma categoria formada por $95 \%$ de profissionais do sexo feminino, que em seu cotidiano de intervenção atende majoritariamente mulheres, permaneceu distante das lutas mais significativas dos movimentos feministas, o que configura, do meu ponto de vista, um desencontro entre o Serviço Social e as questões de gênero.

Esta inquietação tornou-se mais evidente a partir do momento em que assumi a disciplina Supervisão de Estágio, uma vez que, no processo de socialização das experiências em sala de aula, as(os) estudantes trazem à tona o cotidiano de intervenção das instituições onde exercem suas práticas, nas quais surgem de forma significativa demandas que perpassam a questão de gênero: abuso sexual, violência contra mulheres, gravidez na adolescência, dificuldades em relação ao planejamento familiar, direitos reprodutivos, mulheres chefes de família, mulheres idosas vivendo sozinhas e/ou sustentando suas famílias, discriminação no mundo do trabalho, assédio moral, luta por cotas e ações afirmativas, lideranças femininas destacando-se junto aos movimentos e organizações sociais, mulheres encarceradas, aumento do número de mulheres envolvidas com o tráfico de entorpecentes, mulheres com dependência química tanto de álcool como de drogas, crise da masculinidade, discriminação e preconceito em relação à homoafetividade, entre outros.

Neste artigo, proponho discutir e problematizar a construção do conhecimento do Serviço Social, argumentando que ao longo da história andamos em descompasso com os estudos feministas e/ou estudos de gênero, e que esse desencontro contribuiu para consolidar um estatuto acadêmico e uma administração do saber que reproduz a questão de gênero e legitima a dominação masculina.

Parto do pressuposto que o processo de consolidação do Serviço Social no Brasil e na maioria dos países da América Latina foi palco de forte submetimento e "sujeitação" a um tipo de saber eurocêntrico e androcêntrico que deixou marcas profundas na profissão. $\mathrm{O}$ feminismo ${ }^{1}$, por sua vez, seguiu uma trajetória paralela, criticando justamente este androcentrismo, os reducionismos, abrindo-se para teorias críticas contemporâneas e para a interdisciplinaridade. Pretendo contextualizar a crítica a esta história de submetimento do Serviço Social, colocando a questão do conhecimento em relação com a dominação, a partir do que Foucault (1995, p. 5) chama de uma dessujeitação, exercendo a crítica como um processo de leitura que se abre para o debate em função da pluralidade; crítica "como uma arte da indocilidade reflexiva", no jogo do que o autor entende por "política da verdade"2. Três pontos submergem a esse diálogo sobre a nossa profissão.

Uma primeira crítica ao Serviço Social é dirigida aos estatutos acadêmicos da profissão. Em seu processo histórico de consolidação no Brasil e na maioria dos países latino-americanos, o Serviço Social teve como base os princípios da doutrina social da Igreja, que imprimiram na profissão um "espírito de apostolado", configurando-a como uma profissão a ser exercida por mulheres, como uma "vocação", com papéis específicos definidos pela sociedade para mulheres: o cuidado, a tutela, a ajuda, que por sua vez requerem abnegação, entrega de si, ser para os outros, enfim "naturalizando" a responsabilidade da profissão como uma carreira destinada majoritariamente a mulheres.

Mais tarde, com o objetivo de secularizar (ou laicizar) a profissão, o Serviço Social incorporou o discurso do funcionalismo positivista. A tradição científica do positivismo buscaria a verdade partindo de uma concepção de ciência caracterizada pela neutralidade científica, ênfase nas técnicas, com prevalência nas teorias eurocêntricas e descontextualizadas da realidade brasileira.

A partir dos anos 1960, ocorre no Brasil e na América Latina o Movimento de Reconceitualização do Serviço Social. Este movimento teve um importante papel na medida em que pretendeu romper com as teorias importadas e trabalhar na realidade do povo brasileiro. Porém, ao incorporar a teoria marxiana, a profissão sofreu a imposição de uma tendência homogeneizadora de construção do pensamento social, de uma teoria que se pretende universal e prioriza o enfoque de classe, desconsiderando a heterogeneidade do pensamento a partir das dimensões sócio-históricas e culturais que emergem no cotidiano das práticas, entre elas as diferenças sexuais, de identidade, de raça/etnia e de gênero.

Uma segunda crítica é com base na institucionalização da profissão, pois se constata que, nos locais onde exercem sua profissão, as(os) assistentes sociais encontram-se imersos em relações hierárquicas onde predominam correlações de força, de dominação e de poder. Quando tentamos localizar quantas assistentes sociais ocupam ou já ocuparam cargos de poder, direção de uma secretaria de assistência social nos estados ou municípios, Ministérios de Desenvolvimento Social, ou outro cargo representativo em instâncias que executam especificidades da profissão, o que encontramos? Que tipo de instituições contrata assistentes sociais, atualmente? Seriam as(os) profissionais de Serviço Social burocratas contratados pelo Estado para representá-lo junto às políticas sociais? Ou abnegadas/os desempenhando o papel esperado 
pela Igreja em programas ligados à refilantropização da assistência? Como está sendo o reconhecimento e a valorização desta força de trabalho, o piso salarial em comparação aos demais técnicos nas equipes interdisciplinares?

Ainda em relação à institucionalização, perguntamos: qual o papel da Associação Brasileira de Ensino e Pesquisa em Serviço Social (ABEPSS), na formação dos profissionais? Que efeitos de saber e poder possui esta instituição sobre o Serviço Social? O que explica que durante anos seguidos, a mesma figura masculina ${ }^{3}$ é convidada a pronunciar as conferências de abertura, na mesma linha de pensamento, nos encontros e congressos da categoria? A academia também se configura como uma instituição, onde se estabelecem relações hierárquicas, de poder e de dominação e pode constituir-se em centro de produção de um saber hegemônico. $\mathrm{O}$ que significa definir diretrizes curriculares embasadas em uma perspectiva para todas as escolas em nível nacional? Os conceitos estão ligados às referências impostas pelas instituições, ou deveriam ser construídos através das mediações que ocorrem no cotidiano a partir dos contextos socioeconômicos e culturais de cada região?

Uma terceira e última crítica é dirigida ao "discurso técnico" utilizado nas escolas e cursos de formação em Serviço Social. Em uma categoria como "questão social" entendida como "contradição entre capital e trabalho", definida pela ABEPSS como "o objeto" do Serviço Social, ou seja, como "discurso técnico", o que o reducionismo desta categoria não deixa ver? Até que ponto o discurso sobre emancipação política proposto pelo marxismo conseguiu superar o trabalho de cunho assistencialista demandado pelas instituições que contratam profissionais de Serviço Social? Da mesma forma que há uma divisão do trabalho, também há uma divisão linguística, uma hierarquia do discurso; a apropriação de um discurso é a apropriação de uma política da verdade que, por sua vez, marginaliza outras e gera exclusão! Existe uma única verdade para o Serviço Social?

Com esses questionamentos, assumindo uma postura de intelectual engajada em um compromisso ético e político junto à profissão, sugiro que as teorias feministas e os estudos de gênero constituam-se em um aporte teórico-metodológico significativo para o
Serviço Social, uma vez que surgem para questionar todas as formas de dominação, expor novas áreas de conflitos sociais (extrapolando os conflitos de classe), que requerem formas próprias de análises das relações, da construção social da diferença sexual, da sexualidade, da reprodução, da discriminação no trabalho e, sobretudo da cultura, aqui pensada como "práticas que produzem sentido". A grande angústia da maioria das(os) estudantes nos campos de estágio é "como compreender e interpretar as demandas trazidas pelos sujeitos somente com base nos pressupostos da teoria marxiana". Como analisar, por exemplo, a situação de uma criança que sofre abuso sexual se a base da formação teórica deste estudante foi centrada predominantemente na teoria marxiana? Como responder questões que necessitam diferentes dimensões de análises em suas mediações teóricas, quais sejam: explicar o valor diferenciado atribuído ao trabalho dos homens versus o trabalho das mulheres; entender por que o trabalho doméstico e os relativos aos cuidados de doentes, idosos, crianças, não são remunerados, muito menos valorizados; por que ocorre violência contra as mulheres e as meninas? Onde e como se produz essa violência? As verdades dos nossos sujeitos de intervenção, dos nossos entrevistados, muitas vezes são diferentes das nossas. Uma verdade não está prédefinida, ela faz parte de um contingente contextual que deve ser mediado por diferentes concepções teóricas que perpassam as questões de classe, de gênero, de raça/ etnia, que por sua vez se fundamentam em múltiplos tipos de saberes.

Procuro demonstrar que as fronteiras de gênero, da mesma forma que as de classe se entrelaçam para servir a uma grande variedade de funções e análises políticas, econômicas, sociais e culturais. Os estudos de gênero nos convidam a olhar e a pensar de maneira diferente sobre nossa condição histórica e sobre a origem das desigualdades sociais. Convidamnos a extrapolar fronteiras, sermos flexíveis, deixar-nos mover, captar o cotidiano e a realidade das pessoas atendidas nos espaços institucionais: um cotidiano inserido em nucleamentos da esfera da vida, para além da produção. Ou seja, além do trabalho as pessoas têm casa, família, estão envolvidas em relações de afeto, relações de poder ou de violência, são discriminadas, possuem necessidades, desejos! 


\section{As contribuições da teoria feminista para a construção do conhecimento}

Quando pergunto para estudantes ou participantes de oficinas, encontros, reuniões de trabalho, o que significa "feminismo" e se elas se consideram "feministas", a primeira reação da maioria das mulheres é responder: “feminista não, feminina, sim!"'. Isto esclarece que, em relação à concepção de feminismo, permanecem estereótipos relacionados a uma época em que "feminismo" era sinônimo de "um grupo de mulheres mal-amadas, rebeldes e separatistas", consequentemente, malvistas pela sociedade em geral.

Procuro defender, neste artigo, uma concepção ética e política do feminismo. Mostrar que o movimento feminista é um movimento sociocultural, que luta por justiça e equidade nas relações entre homens e mulheres e, sobretudo, luta para garantir os direitos humanos, principalmente o das mulheres em função do alto nível de violência e discriminação que padecem. A partir dos movimentos feministas, a abordagem sobre conflitos e violência na relação entre homens e mulheres, como resultante de uma estrutura de dominação, tornou-se pública.

Ressalto também, que o feminismo tem como pressuposto ético-político denunciar um conjunto de suposições que a sociedade definiu como "natural" (por exemplo, a heterossexualidade, a maternidade), engendram práticas opressivas e discriminatórias, causando sofrimento para as pessoas que fogem do padrão de "normalidade" estabelecido. Os estudos feministas propõem, ainda, desconstruir os papéis impostos a homens e mulheres pela sociedade, com base na tese de que a diferença sexual é o principal fundamento da subordinação feminina.

A teoria feminista tem se constituído, mais particularmente, a partir da década de 1960, como uma teoria crítica e ativista, que estuda as relações de gênero e investiga a situação e as experiências de homens e mulheres, sob uma perspectiva centrada nas mulheres. Considerando-as como sujeitos centrais do processo de investigação, tentando ver o mundo do distinto ponto de vista das mulheres, "com o objetivo de produzir um mundo melhor para as mesmas e, portanto, para toda a humanidade" (LENGERMANN; NIEBRUGGE-BRANTLEY, 1993, p. 355).

Através de um longo estudo sobre a realidade das mulheres, Lengermann e Niebrugge-Brantley traçam uma tipologia de teorias feministas, a partir de três descrições gerais da situação social das mulheres:

1) é diferente da dos homens em termos biológicos, institucionais e sociopsicológicos, diferenças que, ao longo da história, foram transformadas em desigualdades sociais;

2) é desigual a dos homens: as mulheres têm menos recursos materiais, status social, poder e oportunidades para sua autorrealização pes- soal e profissional do que os homens em idêntica posição social, seja esta posição relacionada à classe, raça, ocupação, etnia, religião, educação, nacionalidade ou a outro fator socialmente relevante;

3) é a situação de um grupo oprimido: as mulheres em sua maioria são oprimidas, subordinadas, sofrem violência e são usadas como objeto sexual e de abuso; por sua vez, os opressores são homens ou o sistema social patriarcal construído por homens.

Derivam dessas três situações, as propostas de Lengermann e Niebrugge-Brantley (1993, p. 364) para "as teorias da diferença, da desigualdade e da opressão de gênero". Esta é uma das correntes feministas que surgiram a partir dos estudos de gênero; diferentes circunstâncias históricas moldaram diferentes concepções feministas ao longo da história: liberal, socialista, radical, pós-moderna e outras.

$\mathrm{O}$ pensamento feminista, portanto, tende a ser um conjunto de diferentes correntes teóricas, com múltiplas concepções e pontos de vista; caracteriza-se por ser uma prática política e cultural que busca mudar as estruturas desiguais de poder na sociedade, que luta contra inimigos comuns, como o patriarcado, o sexismo, a exploração, a discriminação, homofobia e outros. Trata-se do esforço de uma comunidade interdisciplinar, que inclui estudiosos de várias áreas como sociologia, antropologia, educação, serviço social, saúde, direito, filosofia, história, psicologia, e outras.

Foram os movimentos feministas que questionaram pela primeira vez a clássica distinção entre o público e o privado introduzindo o slogan "o pessoal é político". Também insistiram em colocar como uma questão política e social, a forma como os sujeitos são generificados ${ }^{4}$, politizando a subjetividade, a identidade e o processo de identificação (como homens/ mulheres), questionando assim o conceito de sujeito do Iluminismo, "indivisível" e unificado, centrado na imagem do "homem" racional, científico, diante do qual se estendia a totalidade da história humana, para ser compreendida e dominada. A teoria feminista passa a desconstruir a dominação do patriarcado e do androcentrismo no campo do conhecimento.

Subitamente, uma parcela da comunidade de intelectuais contemporâneos descobriu que o que havia sido considerado durante muito tempo o universo da experiência era realmente uma visão particularista de atores e experiências masculinas. Portanto, os estudos feministas passam a reconhecer um grupo de atores (atrizes) completamente novo (a metade invisível da história) e propõem uma reconstrução do conhecimento a partir de uma nova compreensão da realidade social, pois segundo Rodriguez (2008, p. 12),

[...] centenas de tratados feitos por sábios reitores do conhecimento: moralistas, teólogos, filósofos, 
cientistas, políticos, escritores, poetas, varões respeitados em todo o tempo e lugar, têm desenvolvido um pensamento excludente e práticas socializadoras repressivas da liberdade das mulheres, para poder sujeitá-las aos seus princípios divinos, biológicos irremovíveis.

Feministas brasileiras também chegaram a esta conclusão dizendo que "o século 20 chega ao fim, confrontando-nos a uma constatação perturbadora: o pensamento tem sido até hoje uma atividade dos homens" (OLIVEIRA, 1992, p.134), e que "a construção do conhecimento e o modo de fazê-lo na modernidade foi definido pela voz dos homens e o silêncio das mulheres" (DIAS, 1994, p.133).

A descrição, a explicação e a análise do mundo social são requisitos de qualquer teoria sociológica. Lengermann e Niebrugge-Brantley (1993, p. 357) argumentam que, do mesmo modo que Marx ajudou os cientistas sociais a descobrir que se pode ver o mundo do ponto de vista dos trabalhadores, sua teoria também muda de modo revolucionário nossa compreensão do mundo, em relação às questões teóricas do feminismo: "o que havíamos considerado um conhecimento universal e absoluto do mundo é, na realidade, um conhecimento derivado das experiências de um segmento poderoso da sociedade, os homens como amos". No entender das autoras, as feministas socialistas avançaram três sentidos importantes no pensamento de Marx: "em sua redefinição das condições materiais, em sua reavaliação do significado de ideologia, e em seu enfoque sobre a dominação, comprovando que esta se exerce de forma polifacética" (LENGERMANN; NIEBRUGGEBRANTLEY, 1993, p. 388).

Com os paradigmas histórico-críticos e culturais, propostos pelo feminismo, somos convidados a adotar uma "perspectiva de gênero" em nossas mediações teóricas, partindo de uma concepção crítica da "visão androcêntrica" da humanidade, que acabou por excluir metade do gênero humano dos espaços socioeconômicos e políticos. A perspectiva de gênero propõe lançar um novo olhar sobre a realidade a partir das mulheres e com as mulheres revolucionando a ordem dos poderes. Centra-se no reconhecimento da diversidade de gênero que implica na reconstrução de uma humanidade diversa e democrática.

Para Lagarde (1996), a crescente incorporação da perspectiva de gênero na elaboração de políticas públicas, as interpretações e os diagnósticos têm permitido a visibilização das mulheres e da problemática que as envolve, assim como avanços na emancipação feminina. A adoção desta perspectiva, porém, requer uma revolução intelectual e cultural e a superação da lógica binária. Sua efetivação contribuirá para a construção de uma nova ordem baseada na perspectiva relacional entre homens e mulheres, de forma equitativa e justa.

\section{Entendendo o desencontro entre feminismo e Serviço Social}

As origens do Serviço Social se encontram na revolução industrial ocorrida no século 19 na Inglaterra. A profissão surge, por um lado, em função das condições precárias de vida da população que havia emigrado em massa do campo para a cidade, e, por outro, com o compromisso da Igreja (geralmente a católica), no esforço de aliviar a miséria e assegurar certo poder na sociedade.

No Brasil, a profissão surge na década de 1930, ligada à intervenção progressiva do Estado nos processos reguladores da vida social. Segundo Wanderley e Yazbeck (2007), o Serviço Social adquire uma dimensão institucional legítima quando o Estado passa a utilizá-lo como um meio e a Igreja Católica como apoio para fazer frente aos crescentes problemas sociais. Em 1932, é criado o Centro de Estudos e Ação Social de São Paulo (CEAS) e a partir deste, surgiram os Centros Operários, onde as "moças formadas" atuavam junto às operárias por meio de aulas de tricô, trabalhos manuais, conselhos sobre higiene, estudando o ambiente e as necessidades das famílias (CARVALHO; IAMAMOTO, 1990). Em 1936, é fundada a primeira Escola de Serviço Social, precursora da atual Faculdade de Serviço Social da Pontifícia Universidade Católica de São Paulo (PUC-SP).

Até a profissão de Serviço Social consolidar suas bases, ocorreram no Brasil muitos movimentos de mulheres: em 1832, Nísia Floresta já havia publicado Direitos das mulheres e injustiça dos homens; em 1910, foi fundado o Partido Republicano Feminino (PFR); em 1927, as líderes da Federação Brasileira para o Progresso Feminino realizaram um "abaixo-assinado" com 2.000 assinaturas exigindo o direito de voto às mulheres, e em 1932 o novo Código Eleitoral dá o direito ao voto à mulher, no Brasil; em 1948, foi criada a Federação das Mulheres no Brasil, com o objetivo de organizar campanhas contra a carestia e lutar pela libertação das presas políticas (PINTO, 2003).

A categoria profissional de assistentes sociais se consolida, e, em 1946, é criada a Associação Brasileira de Escolas de Serviço Social (ABESS); o primeiro Código de Ética Profissional do Assistente Social é aprovado em assembléia geral da Associação Brasileira de Assistentes Sociais (ABAS), em 29 de setembro de 1947; até 1949, foram criadas 15 escolas de Serviço Social no Brasil. A profissão de assistente social é regulamentada no Brasil, pela Lei n. 3.252, de 27 de agosto de 1957. Nos anos 1960, Talcon Parsons era o teórico social cujo ponto de 
vista sobre a família, e os papéis atribuídos aos homens e as mulheres nas sociedades modernas, constituía o discurso convencional ${ }^{5}$

A década de 1960 traz contribuições significativas para o feminismo: chegam ao Brasil obras como: O segundo Sexo, publicado por Simone de Beauvoir, em 1949, na França, e A Mística Feminina, publicado por Betty Friedman, em 1963, nos Estados Unidos. Surge o movimento hippie e a pílula anticoncepcional; os primeiros núcleos de estudos feministas surgem nessa época. Em 1964, tem início a ditadura militar no Brasil, várias mulheres são presas e torturadas e as esposas ou companheiras de presos políticos criam o Movimento pela Anistia. Em 1969, a socióloga Heleieth Saffioti, considerada uma das grandes precursoras dos estudos sobre a condição feminina no Brasil, publica $A$ mulher na sociedade de classes. Em 1975 é proclamado o Ano Internacional da Mulher e a ONU estabelece o dia 8 de março como o Dia Internacional da Mulher.

Ainda na década de 1960, o Serviço Social inicia um movimento de reconceituação da profissão em toda a América Latina; é introduzida a perspectiva marxiana nos cursos, busca-se trabalhar numa perspectiva de Serviço Social comprometido com as classes trabalhadoras; a partir de 1964, a perspectiva crítica adotada pelo Serviço Social com o processo de reconceituação passa a ser alvo de repressão pelo golpe militar e ocorre uma fiscalização nos currículos e conteúdos ministrados nas escolas. Nessa época, ainda no regime militar, a questão social foi enfrentada pelo binômio "repressão" e "assistência"; no período em que se processou a chamada "abertura política”, ou seja, a partir de 1980, profissionais do Serviço Social, inseridos na militância política e honrando o compromisso com a classe trabalhadora, passam a atuar como assessores de diferentes movimentos sociais.

Em 1980, inaugura-se o debate da ética no Serviço Social, assume-se claramente no Código de Ética Profissional, aprovado em 1986, a ideia de "compromisso com a classe trabalhadora"; a partir de 1980, profissionais de Serviço Social desenvolvem projetos de extensão junto a comunidades de periferia seguindo os pressupostos teórico-metodológicos da teologia da libertação: "opção pelos oprimidos", e se inserem nos trabalhos ligados às chamadas "Comunidades Eclesiais de Base". Algumas profissionais de Serviço Social, de forma isolada, integram movimentos feministas.

A década de 1980 é marcada por eventos significativos decorrentes das lutas e reivindicações dos movimentos feministas: em 1980, é criado em São Paulo o SOS Mulher; em 1983 são criados os Conselhos Estaduais e Municipais de Direitos da $\mathrm{Mu}-$ lher e dois anos depois surge a primeira Delegacia Especializada de Atendimento a Mulheres Vítimas da Violência (DEAM), em São Paulo. A atuação dos movimentos feministas foi fundamental para garantir, na Constituição Brasileira de 1988, os direitos das mulheres. Sob o slogan: "Constituinte sem a participação das mulheres é constituinte pela metade", grupos de mulheres em todo o Brasil, realizaram passeatas, colheram assinaturas em abaixoassinados que foram enviados para os parlamentares em Brasília, exigindo direitos na nova Constituição (PINTO, 2003).

Em 1990, surge na academia a categoria gênero consolidando os "estudos de gênero" em substituição a "estudos feministas" ou "da condição feminina". Aproximando-se dos movimentos feministas, a partir de 1990, o Serviço Social passa a aderir às lutas das chamadas minorias, inserindo-se nas questões relacionadas à violência contra mulheres, discriminação étnica, racial e cultural, homofobia e outras.

O ano de 1993 é palco de uma grande conquista para a categoria profissional com a promulgação da Lei Orgânica da Assistência Social (LOAS) - Lei n. 8.742/93 - que organizou a Assistência Social no Brasil e instituiu o Conselho Nacional de Assistência Social (CNAS). No mesmo ano, é aprovado o novo Código de Ética do Assistente Social, reafirmando os princípios fundamentais da atuação profissional em defesa da equidade, da justiça social e dos direitos humanos. Também em 1993, a ABEPSS define as diretrizes curriculares para os cursos de Serviço Social, definindo "a questão social" como o objeto da profissão, em todo o território nacional.

Em meados da década de 1990, surgem núcleos de estudos e pesquisas sobre as temáticas de gênero, violência e outros em todo o Brasil, e a partir de 2000 são propostos eixos específicos que contemplam a temática de gênero articulada ao Serviço Social nos encontros da categoria, Congresso Brasileiro de Assistentes Sociais (CBASS) e Encontro Nacional de Pesquisa em Serviço Social (ENPESS).

Em 2003, é criada a Secretaria Especial de Políticas para Mulheres, com status de Ministério, com a finalidade de propor e executar políticas públicas que levem em conta a igualdade de gênero; em agosto de 2006, fruto de uma longa caminhada de grupos feministas organizados ao longo de todo o país, é promulgada a Lei n. 11.340 - Lei Maria da Penha, que dispõe sobre o enfrentamento à violência doméstica e familiar contra as mulheres.

Constatamos que ao longo da história houve mais desencontros do que encontros entre o Serviço Social e as questões de gênero. A partir dessa trajetória, como recuperar esse descompasso, ou seja, como promover um encontro com a articulação desses dois enfoques? Como vislumbrar possibilidades de aproximação teórica e propostas de intervenção no cotidiano de nossas práticas? 


\section{Propondo um encontro, (ou um reencontro) entre os estudos de gênero e o Serviço Social}

O cotidiano profissional das(os) assistentes sociais tem se confrontado com um leque de situações que caracterizam exclusão, discriminação, exploração, opressão, desigualdade social, relações de poder, de violência, entre outras. De forma pulverizada, quando não isolada, algumas(uns) profissionais de Serviço Social têm se aproximado dos estudos de gênero e insistido na importância da transversalidade dessa categoria na mediação teórica sobre as demandas que surgem no cotidiano das práticas.

Nesse contexto, os estudos de gênero têm contribuído para decifrar alguns questionamentos: por que ao longo da história, a diferença sexual tem sido a principal causa da subordinação feminina? Como entender os altos índices de violência contra mulheres e abuso sexual contra meninas? Por que as experiências de mulheres e de homens têm sido construídas de forma diferenciada? O que explica as hierarquias sexuais e as distribuições desiguais de poder na sociedade? Como se assumem identidades femininas e masculinas consideradas fora do padrão de "normalidade" estabelecido pela sociedade?

A categoria gênero é recente no meio acadêmico e tem sido palco de várias discussões teóricas. Scott (1995, p. 77) argumenta que a busca de legitimidade acadêmica levou as estudiosas feministas, nos anos 1980, a substituir o termo mulheres por gênero. Para autora, "'gênero' parece ajustar-se melhor à terminologia científica das Ciências Sociais." É uma categoria utilizada para designar as relações sociais entre os sexos, uma vez que não existe um mundo das mulheres separado de um mundo dos homens:

[...] a informação sobre as mulheres é necessariamente informação sobre os homens, um estudo implica o outro. Este uso insiste em que o mundo das mulheres é parte do mundo dos homens, criado nele e por ele. Este uso rejeita a utilidade interpretativa de esferas separadas [...] (SCOTT, 1995, p. 80).

O centro da sua definição de gênero é a articulação entre duas ideias: "o gênero é um elemento constitutivo das relações sociais baseadas nas diferenças que distinguem os sexos e o gênero é uma forma primária de relações de poder". O ensaio de Scott possui vários méritos. Um deles é o questionamento ao essencialismo e à historicidade: "necessitamos rejeitar a qualidade fixa e permanente da oposição binária para alcançar uma historicidade e uma desconstrução genuínas dos termos da diferença sexual" (SCOTT, 1995, p. 80/86).

Para a antropóloga Lamas (2008, p. 340) "o que define o gênero é a ação simbólica coletiva". Median- te o processo de constituição da ordem simbólica em uma sociedade, fabricam-se as ideias do que devem ser e como devem agir homens e mulheres. Bourdieu explica esse processo através da "lógica de gênero": "é uma lógica de poder e de dominação; é a forma paradigmática de "violência simbólica", ou seja, aquela violência exercida sobre um agente social com sua cumplicidade e seu consentimento" (BOURDIEU, 1988 apud LAMAS, 2008, p. 345). A lógica de gênero também funciona como uma instituição inscrita por milênios na objetividade das estruturas sociais e na subjetividade das estruturas mentais.

Para Bourdieu (1999), a ordem social masculina está tão profundamente arraigada que não requer justificação: impõe a si mesma como autoevidente, e é tomada como "natural", graças ao acordo quase perfeito e imediato que obtém, por um lado, das estruturas sociais e, por outro, das estruturas cognitivas inscritas nos corpos e nas mentes. Mediante a lógica do "gênero", por exemplo, ocorre uma "naturalização" da heterossexualidade excluindo a homossexualidade de uma valoração simbólica equivalente aceitável. Em nossa cultura, a homossexualidade é vista como "fora" da lógica de gênero e tem um estatuto simbólico, moral, jurídico diferente da heterossexualidade, ou seja, está fora da "lei social". "Decorrente desse fato existe um grande número de pessoas cujas vidas estão em conflito aberto e permanente com a sociedade" (LAMAS, 2008, p. 348). Como podemos garantir igualdade com respeito às diferenças?

Scott (1994) insiste que a noção política da igualdade inclui um reconhecimento da existência da diferença, mais ainda: depende de tal reconhecimento. Ninguém é igual a ninguém. As exigências de igualdade se basearam sempre em argumentos implícitos e geralmente não reconhecidos em favor da diferença: se os indivíduos ou grupos fossem idênticos entre si mesmos, não haveria necessidade de pedir igualdade. A mesma igualdade pode definir-se como uma diferença deliberada frente a diferenças específicas.

Para a autora, mulheres e homens não estão reivindicando uma mesma identidade (serem idênticos) nem uma igualdade. A questão é negar-se a opor igualdade e diferença e insistir na existência das diferenças - diferenças como condição de identidades coletivas e individuais, diferenças como negação à fixação de identidades, diferença como o verdadeiro significado da igualdade política e social, que por sua vez, requer equidade, ou seja: "tratar diferentemente os desiguais".

Com o objetivo de garantir equidade de gênero, o Fórum de ONGs realizado na China ${ }^{6}$ em 1995 identificou algumas áreas críticas que impedem o desenvolvimento das mulheres e demarcam a desigualdade de gênero. Em cada uma dessas áreas, emergem situações no cotidiano de atendimento das(os) assistentes sociais, nas quais é possível acrescentar observações e constatações: 
a) "a persistente e crescente carga de pobreza que recai sobre as mulheres" - as mulheres constituem-se nas principais usuárias dos Programas de Assistência Social; 30\% de famílias no Brasil são chefiadas por mulheres;

b) "a desigualdade de acesso a serviços de saúde e educação" - os índices de morte materna ainda são grandes no Brasil; os direitos reprodutivos não são respeitados, o aborto ainda é considerado crime e, em caso de gravidez indesejada, a responsabilidade é atribuída somente às mulheres; um grande número de adolescentes deixa de estudar porque engravidam;

c) "a violência contra as mulheres e crianças" física, psicológica, sexual, patrimonial; a secular "dominação masculina" ainda admite a superioridade do homem que se acham no direito de exercer poder sobre o corpo das mulheres e meninas (geralmente filhas);

d) "a desigualdade no acesso às políticas e estruturas econômicas" - criar oportunidades para as mulheres participarem dos mecanismos de planejamento e gestão de programas que contemplem a equidade de gênero;

e) "a desigualdade entre homens e mulheres no que diz respeito à distribuição do poder e tomada de decisões" - garantir a paridade em relação à ocupação de cargos políticos e representativos;

f) "os insuficientes mecanismos de promoção da condição da mulher" - inserir a transversalidade de gênero nas políticas públicas, garantir eixos que venham ao encontro das necessidades básicas das mulheres e de suas famílias; capacitá-las para exercer uma ocupação remunerada e possibilitar seu empoderamento;

g) "o insuficiente uso dos meios de comunicação de massas para promover a contribuição positiva da mulher à sociedade".

As políticas e as ações afirmativas para mulheres são, atualmente, as medidas mais concretas para garantir a equidade de gênero. Os princípios éticos das ações afirmativas devem concentrar-se na compensação, na reparação, na equidade e na justiça. A equidade de gênero se refere à distribuição justa de direitos, oportunidades, recursos, responsabilidades, tarefas entre os gêneros respeitando as diferenças entre homens e mulheres. Pressupõe, ainda, ações para dotar as mulheres dos instrumentos, recursos e mecanismos necessários para participar e deixá-las preparadas para exercer cargos, propor e participar das decisões que lhe dizem respeito.

Equidade, para Lagarde (1996, p. 216), consiste em que as mulheres sejam educadas e tratadas como seres humanos com direito à integralidade de seu corpo e de sua pessoa, ao respeito, aos cuidados e à obtenção dos bens materiais e simbólicos necessários para o seu desenvolvimento pessoal.

É preciso destacar que a incorporação do debate sobre a equidade de gênero nas políticas públicas, no Brasil, é resultado de um longo processo social e político de participação, sustentado em grande medida pela visibilidade e legitimidade que os movimentos feministas têm alcançado nos últimos 20 anos. Também, pela produção de conhecimento sobre a temática das relações de gênero, e pela resistência das mulheres no cenário político e social como sujeitos sociais, cujas demandas questionam a estrutura de poder e a organização da vida cotidiana baseada na dominação masculina. Assim, colocam no centro dos debates o tipo de democracia em exercício, lutando para afirmar a democracia de gênero como estratégia de empoderamento não só político, mas também socioeconômico e cultural das mulheres.

\section{Considerações para debate}

Retomando a proposta colocada no início deste ensaio, reitero a necessidade de estabelecermos uma relação entre o processo histórico de institucionalização do Serviço Social com os saberes que constituíram a nossa profissão e as relações de dominação, questionando os "modos de subjetivação" a que ficam submetidas(os) um grande número de profissionais.

Ciente de que as questões problematizadas neste ensaio apontam elementos para um profícuo debate, proponho que as mulheres que constituem a maioria das profissionais de Serviço Social, e também os colegas homens, aproximem-se das contribuições dos estudos de gênero, e que no cotidiano das práticas possam incorporar reflexões teóricas que iluminem as demandas que surgem no exercício profissional.

As principais correntes do feminismo tem se caracterizado como ativismo político e reflexão acadêmica, com o objetivo de denunciar a apropriação de um discurso como única verdade e as hierarquias no espaço acadêmico. O feminismo tem despontado na cena política como um dever/denúncia: há uma crescente percepção, por parte do movimento de mulheres (conferências mundiais) sobre a necessidade de transcender o modelo industrial orientado para o consumo, exigir respeito ao corpo das mulheres, descriminalizar o aborto, acabar com a impunidade em relação aos altos índices de violência e com a homofobia; reivindicar responsabilidade por parte dos meios de comunicação ao difundirem imagens que denigrem a mulher como objeto sexual, entre outras.

O feminismo tem se imposto como uma "estratégia de resistência", reinventando as mulheres, reinventando "uma fala", um saber submetido, constituindo comunidades de debate, garantindo o direi- 
to de questionar, desconstruindo os papéis impostos pela sociedade. Nesse sentido, para a filósofa Ana Maria Martinez de Escalera ${ }^{7}$, "Feminismo Estratégico" implica em um "labor" filosófico uma vez que "ser" e "saber" não podem separar-se. A partir da concepção de "Feminismo Estratégico" da autora, entende-se como necessário que as(os) assistentes sociais se reconheçam como sujeitos históricos, com capacidade para utilizar ferramentas que deslegitimem uma visão estabelecida de realidade social, descronstruindo o sujeitamento da profissão ao longo da história e constatando que o Serviço Social no Brasil tem passado por sucessivas crises de identidade, justamente porque o discurso imposto pela academia não condiz com as práticas do cotidiano que envolvem incessantemente dimensões da vida que vão além da classe. $\mathrm{O}$ "Feminismo Estratégico" nos instiga a perguntar: como "trabalhadores sociais", que técnicas podemos utilizar para saber o que fazem, o que pensam e o que desejam os sujeitos de nossas práticas? Como podemos reproduzir suas experiências contadas em discursos "não colonizados"? Que estratégias de resistência podemos utilizar para "dessujeitar-nos" da dominação masculina?

Concordamos com Corine D'Souza quando afirma que "o feminismo é para as ciências sociais um deslocamento de paradigma, e para os movimentos sociais uma ruptura. Ele traz para o mundo novos significados, novas esperanças" (D'Souza, 1986, apud Oliveira, 1992, p.135).

É possível concluir que, para dessujeitar-se do pensamento dominante que fez parte da historia da profissão, o Serviço Social deve aproximar-se dos estudos feministas para realizar uma crítica a partir de seu submetimento, a uma verdade, a uma linguagem, a um discurso, a uma história colonizada. E necessário inventar, reinventar uma nova forma de produzir conhecimento em Serviço Social a partir da afirmação da nossa identidade e a partir das demandas que surgem no cotidiano de nossas práticas que configuram a transversalidade de gênero!

\section{Referências}

BOURDIEU, P. A dominação masculina. Rio de Janeiro: Bertrand Brasil, 1999.

CARVALHO, R.; IAMAMOTO, M. Relações sociais e Serviço Social no Brasil - esboço de uma interpretação histórico-metodológica. São Paulo: Cortez, 1990.

CASTRO, E. El vocabulario de Michel Foucault: un recorrido alfabético por sus temas, conceptos y autores. Buenos Aires: Bernal; Universidad Nacional de Quilmes, 2004.
CONWAY, J. K.; BOURQUE, S. C.; SCOTT, J. El concepto de género. In: LAMAS, M. (Comp.). El género - la construcción cultural de la diferencia sexual. Programa Universitario de Estudios de Género. Universidad Autónoma de México: México, 2003. p. 21-33.

DIAS, M. O. da S. Novas subjetividades na pesquisa histórica feminista: uma hermenêutica das diferenças. Revista de Estudos Feministas, Rio de Janeiro, CIEC/ECO/ UFRJ, v. 2, n. 2, 1994.

FOUCAULT, M. Crítica y Aufklärung [“QQu'est-ce que la Critique?']. Tradução de Jorge Dávila. Revista de Filosofia, Universidad de Los Andes (ULA), Mérida, Venezuela, v. 8, 1995.

. A história da sexualidade 1-A vontade de saber. Rio de Janeiro: Graal, 1997.

LAGARDE, M. Género y feminismo - desarrollo humano y democracia. Madrid: Horas \& Horas, 1996.

LAMAS, M. (Comp.). El género - la construcción cultural de la diferencia sexual. Programa Universitario de Estudios de Género, Universidad Autónoma de México, México, 2008.

LENGERMANN, P.M.; NIEBRUGGE-BRANTLEY, J. Teoria feminista contemporânea. In: RITZER, G. Teoria sociológica contemporânea. Madri: Mcgraw-Hill, 1993, p. $353-409$.

OLIVEIRA, R. Memórias do planeta fêmea. Estudos Feministas, Rio de Janeiro, UFRJ, v. 0, n. 0, 1992. p. 131142.

PINTO, C. R. J. Uma história do feminismo no Brasil. São Paulo: Fundação Perseu Abramo, 2003. (Coleção História do Povo Brasileiro).

RODRIGUEZ, M. E. S. Hijas de la igualdad, herederas de injusticias. Madri: Narcea, 2008.

SCOTT, J. W. Desconstruir igualdad-versus-diferencia: usos de la teoria posestructuralista para el feminismo. Feminária, Buenos Aires, ano VII, n. 13, nov. 1994.

. Gênero: uma categoria útil de análise histórica. Revista Educação \& Realidade. Porto Alegre, UFRGS, v. 20, n. 2, jul./dez. 1995.

WANDERLEY, M. B.; YAZBECK, C. El Servicio Social en Brasil: origen, prácticas y desafíos. In: DESLAURIERS, J.P.; HURTUBISE, Y. (Dir.). El Trabajo Social internacional - elementos de comparación. Buenos Aires: Lumen; Humanitas, 2007. p. 139-159. 


\section{Notas}

1 Neste artigo utilizo a concepção de feminismo como uma corrente política que nasceu na modernidade e tem cruzado a história contemporânea desde a Revolução Francesa até a atualidade. Como outros movimentos sociais, o feminismo tem gerado correntes de pensamento e uma ação política a favor de uma mudança nas condições de opressão entre os sexos. Tenho claro que não existe um só movimento feminista, mas sim, um amplo conjunto de grupos e expressões sociais com distintas posturas políticas, lutando por um mesmo fim que é a emancipação das mulheres, em sentido pleno.

2 Cada sociedade, diz Foucault, tem seu regime de verdade, sua "política geral sobre a verdade", ou seja, os tipos de discursos que ela aceita e faz funcionar como verdadeiros ou falsos; os mecanismos e as instâncias que permitem distinguir os enunciados verdadeiros ou falsos, a maneira em que se sancionam uns e outros; as técnicas e os procedimentos que são valorizados para a obtenção da verdade; o estatuto daqueles que possuem a função de decidir o que funciona como verdadeiro (FOUCAULT, 1985, apudCASTRO, 2004, p. 345).

3 Esta observação independe do respeito e da consideração que tenho pelas notáveis contribuições que o conferencista tem dado para a construção do conhecimento da nossa profissão.

4 Esta categoriaé construída por Scott (1995,p. 75) para quem o conceito de gêneroé "um elemento constitutivo de relações sociais fundadas sobre as diferenças percebidas entre os sexos."

5 Seus três ensaios no volume Family, Socialization and Interaction Process (1955), escritos no início dos anos 1950, sustentavam que os papéis de gênero possuíam um fundamento biológico e que o processo de modernização havia conseguido racionalizar a atribuição desses papéis como naturais. A visão parsoniana de "gênero" aceitava sem questionar as características do comportamento sexual normal e do temperamento elaboradas por cientistas sociais das décadas de 1930 e 1940, e considerava toda a variação destas normas como um desvio (CONWAY; BOURQUE; SCOTT, 2003).

6 As principais conclusões tiradas neste Fórum foram publicadas no documento: IV Conferência Mundial sobre as Mulheres - Beijing, China, 1995. Disponível em: <www.icieg.cv>.Acesso em: 23 set. 2009.

7 A categoria "Feminismo Estratégico" foi construída pela professora juntamente com o grupo integrante do Seminário Alteridad y Exclusion, do qual participamos durante o nosso Estágio Pós-Doutoral, no segundo semestre de 2009, na UNAM, México. As reflexões trazidas têm como base os apontamentos em sala de aula.

\section{Teresa Kleba Lisboa}

tkleba@gmail.com

Doutorado em Sociologia pela Universidade Federal

do Rio Grande do Sul (UFRGS)

Pós-Doutorado no Programa de Estudos de Gênero da UNAM, México

Professora dos Cursos de Graduação e Pós-Graduação em Serviço Social da Universidade Federal de Santa Catarina (UFSC)

Coordenadora do Núcleo de Estudos e Pesquisas em Serviço Social e Relações de Gênero (NUSSERGE)

\section{UFSC - Departamento de Serviço Social}

Centro Sócio-Econômico

Campus Universitário - Trindade

Florianópolis - Santa Catarina

CEP: 88010-970 